\title{
THE CONTINGENCIES OF CHINESE DIASPORIC IDENTITIES IN CHARLSON ONG'S SPECULATIVE FICTION
}

\author{
Joseph Ching Velasco \\ De La Salle University - Manila \\ FEU Institute of Technology \\ jcvelasco@feutech.edu.ph
}

\begin{abstract}
Charlson Ong's award-winning novel An Embarrassment of Riches (2000) creatively narrates the history of the Chinese diaspora as an overdetermined event in the Southeast Asian Region. The novel explores the politics of belonging, displacement, identity, and territory through $\mathrm{a} / \mathrm{n}$ (re)imagined nation built primarily on Philippine historical and cultural contingencies. This essay seeks to explore the junctures and vicissitudes of the Chinese diaspora in the region through the following questions: How is hybridity manifested by selected characters and other cultural elements in the narrative? Second, how do the perceptions of homeland, marked by ambivalence and contradiction, operate in the narrative? And third, how does the memory of the characters' homeland or the lack of it contribute to identity formation? Furthermore, an analysis of the novel's form has been conducted, possibly asserting the notion that the genre is also a hybridized entity. This paper illustrates the complexity of the Chinese diaspora in the region and its bearing to identity formation.
\end{abstract}

\section{Keywords}

Charlson Ong, Chinese Culture, Chinese Diaspora, Chinese Filipino Identity, Genre, Southeast Asia, Speculative Fiction

\section{About the Author}

Joseph Ching Velasco is a graduate student of the Behavioral Sciences Department of De La Salle University - Manila. He is currently working on his PhD in Sociology. Furthermore, he holds a master's degree in language and literature from DLSU. He is also a full-time faculty member of the Humanities, Social Science, and Communication Department of FEU Institute of Technology. 
In the broad field of Postcolonial Studies, "diaspora" has emerged as a critical term to challenge the force of the putatively non-pliant borders of cultural nationalism by interrogating dominant notions of identity and cultural belonging in post-colonial societies. These societies have a necessary investment, for better and then for worse, in the idea of the nation. Paul Gilroy's landmark contributions in the theorizing of the "double consciousness" endemic in diasporic identities have recuperated the concept of "diaspora" as a critical tool necessary in frustrating the tendency towards cultural exclusivity that is often endorsed by the nation, for it "offers a ready alternative to the stern discipline of primordial kinship and rooted belonging" (Against Race 123). Forcefully echoing Gilroy's position is the work of Stuart Hall who sees the diasporic experience as defined, not by essence or purity, but by the recognition of necessary heterogeneity and diversity-a conception of identity that lives in and through difference and hybridity (cited in Braziel and Mannur 5). However, while this study draws both intellectual and ethical inspiration from those works, it remains aware of the dangers of uncritical generalization that might homogenize profoundly different post-colonial experiences. I assert that the critical value of "diaspora" is increased by paying attention to diasporic experiences that do not necessarily fit the models from which Gilroy's pronouncements emerge. For example, while Gilroy seems to effortlessly frame the relation of diaspora and nation as clearly adversarial, our understanding of diaspora, informed by the experience of Chinese Filipinos and in particular as reimagined by the fiction of Charlson Ong, shows a more ambivalent relation between those two terms. The succeeding generations of Chinese Filipinos readily accepted the Philippines as a permanent home from their sojourn. This phenomenon reframes the relationship between nationalism and diaspora that Gilroy positioned as oppositional. Likewise, the process of diaspora, despite being primarily discordant, allowed Chinese Filipinos to reimagine their national position for a more prominent social integration.

Caroline Hau in Necessary Fictions has observed that while the Chinese "constitute a foreign presence...they are a familiar foreign presence. Which is to say, the place they occupy in Philippine society is at once clear-cut and ambiguous, defined yet also indeterminate" (134; emphasis added). Furthermore, the Chinese in the Philippines are "variously identified with capitalism, communism, and cultural chauvinism, and viewed as economically dominant, politically disloyal, and culturally different" (Hau, The Chinese Question 58). The reason for this curious form of belonging has complex and overdetermined reasons. And while it is beyond the scope of this essay to provide a comprehensive historical account of the Chinese in the Philippines, I offer a brief sketch of that history if only to provide common ground on which our discussion may unfold. Historical accounts of the Chinese diaspora in the Southeast Asian region mark their presence in what would later become the Philippine republic before the arrival of the Spaniards 
(Tong 202). While the Philippines was under the colonial rule of Spain, the Chinese were initially encouraged by the Spaniards to expand their economic activities. However, with the increase of the Chinese population and immigration in the Philippines, the Spaniards became concerned and apprehensive. Controlling the Chinese population in the Spanish colonial era was conducted through segregation, conversion, and even massacre (Tong 202). On the other hand, the American colonial government encouraged them to continue their businesses and other cultural practices. This is exemplified through the rise of Chinese community institutions such as the Kwantung Hui-Kwan (Cantonese Association), Shan-Chu Kung-So (Chinese Charitable Association), and Kwan-Ti Yeh-Hui (the God of War and Commerce Association). Furthermore, it gave rise to Chinese hospitals and newspapers (Tong 202).

The Chinese diaspora has certainly played a part on the economic, political, and cultural development of the nations affected by their movements and migrations. The diasporic Chinese also influenced the artistic and literary production of the receiving countries. Ananya Kabir opines that the experience of cultural displacement resulting from diaspora creates spaces for reflection on the "divergence of official histories and private traumas" that are present in various generations (146). As for the creative intellectual who is part of the diasporic experience, the moments of arrival and departure seem to be significant junctures. These diasporic markers are loaded with affective significance and potentials that will resonate strongly in their artistic expressions.

While numerous studies have ably explored the socio-historical dimensions of the Philippine-Chinese diaspora, this paper confines its inquiry to the domain of representation, particular in Charlson Ong's novel An Embarrassment of Riches. While the analytical provenance of this paper is literary, I am nevertheless convinced that it will generate a meaningful intervention in properly historicizing key issues in diaspora studies such as hybridity ${ }^{1}$ and cultural belonging. Specifically, this paper seeks to interrogate the concepts in diaspora studies such as identity and hybridity vis-à-vis An Embarrassment of Riches. In the end, I seek to show that an enabling ambivalence troubles any figuring of diasporic identities as oppositional to the nationalist project, and ultimately foregrounding a "(postcolonial) consciousness that understands the disjunctive and fractal qualities of modernity and that consequently anticipates the imagining of new anticolonial futures" (De Chavez 84). This enabling ambivalence shows the nuances of the formation of diasporic identities, an aspect that is intricately tied with cultural heritage and even the nation. Towards this goal, I give privileged attention to the work of Charlson Ong who is recognized as among the important voices in Chinese Filipino literature. The Chinese Filipino writer is a figure that might be regarded as a "person inprogress," writing about his or her unique and solitary experience of being Chinese 
Filipino but necessarily locating that experience within a larger neglected history of hybrid heritage. ${ }^{2}$ As for Charlson Ong's cultural, educational, and religious background, he was brought up as a "Catholic Filipino [who was] required to learn Chinese language and history and was growing up in a distinct subculture" (Ong, "China is in the Heart" 144). In his narratives, he explores the intricate diasporic phenomenon that traverse the existence of Chinese Filipinos in almost all walks of life as can be seen in An Embarrassment of Riches.

The novel's title An Embarrassment of Riches signifies an overabundance of wealth. The novel's title seems to point to the excesses in the narrative; in particular, the abounding accumulation of wealth, power, and influence of a select few. It seeks to negotiate the ideas and concepts of history and narrativity, spatial and cultural territories and locales, and the terrains of identities and subjectivities. The novel, Charlson Ong's first, won second place for the Philippine Centennial Literary Prize.

\section{CROSSING THE BORDERS OF THE DIASPORA: THE POLITICS OF ROOTEDNESS, ROOTLESSNESS, AND UNBELONGING}

The novel is an exploration of an identity that is in-between, which is dramatized by the novel's protagonist Jeffrey Tantivo. As the main agent of the narrative, Jeffrey Tantivo's understanding of his identity is rooted in the complicated history of his family's movement to a new country. Putting Jeffrey Tantivo's diasporic circumstance into perspective, his travails show the curiously close association of exile and return. In the novel, both the tropes of exile and return are used to underscore the tension between national belonging and otherness. Born in the Victorianas, he goes to the Philippines briefly en route to the US, to study medicine. However, a series of unfortunate events occur in his preliminary stay in the Philippines. Those hindrances hamper his chances of claiming the "Victoriano Dream." While away, the Victorianas is further plagued by a panoply of sociocultural and political problems.

The Chinese immigrants in the Victorianas are highly supportive of the regime to protect their own interests. They are "first silently supportive of a ruler who could restore order and prevent hooligans from burning Chinese homes and businesses" (Ong 20). That is to say, they have tolerated the regime as they are given "every privilege short of full-fledged citizenship" (21). Overall, race relations within the country are not equal as the Chinese succumbs to the impulse of the state.

Being exiled abroad, Jeffrey Tantivo participated in the affairs of the Victorianas remotely by writing for the newsletter "Partisano Victoriano" that keeps "the flame 
of democracy alive in their hearts" (Ong 24). This strong connection to the islands begins in childhood.

Yes. I was a Victoriano, born and bred in that southwestern Pacific island of twenty million, raised in the ever-loyal and Catholic capitol of San Ignacio, who had sung the national anthem "Salvacion para Los Bravos" since I was five and was taxed ten centavos for every candy I bought. (10)

Jeffrey Tantivo shows his strong commitment to his land of allegiance, despite not being recognized as its citizen. Caroline Hau notes that acquiring citizenship for the diasporic Chinese is not an easy feat. The process is "protracted, difficult, and expensive" given that the cultural and economic construction of the Chinese as "aliens" (The Chinese Question 59).

Despite Jeffrey Tantivo's strong connection to the Victorianas, his recollections of the nation seem to be alien and unfamiliar. This is revealed in his rumination after his immediate return to the Victorianas, he states "I tucked into the back seat, shaken and bruised, wished so fervently that I had never set foot again in my beloved homeland" (Ong, Embarassment of Riches 81). His ambivalence for the Victorianas is symptomatic of a fragmented psyche. Considering his nationalistic temperament vis-à-vis his land of birth; the ambivalence toward the Victorianas abounds and underscores his being as an individual of multicultural influences. It is however from this hybrid positionality, rather than from notions of cultural purity, that grounds Jeffrey's fervent idealism and desires to reform his homeland.

To further elaborate, he is a non-citizen of the Victorianas but continues his sojourn as if he is a full-fledged citizen. This ironic positioning of the character in the narrative calls attention to the issue of citizenship not simply as a political terminology but as a psychological subjectivity in light of problematic hybrid identities. The simultaneity of both love and hate directed to the Victorianas also foregrounds Jeffrey's puzzling identification. Radhakrishnan provides an explanation on why ambivalence is endemic in diasporic identities. He states that "it is quite customary for citizens who have emigrated to experience as a form of critical enlightenment or a healthy 'estrangement' from their birth land, and to experience another culture or location as a reprieve from the orthodoxies of their 'given' cultures" (126). The complexity of dealing with Jeffrey Tantivo's problematic identification is mediated through the inversion of citizenship, that is, of not wanting to belong to the island-nation but desiring to be a citizen of the world. Coming into terms with these contrasting emotions and outlook, Jeffrey reveals his identity politics in an essay written in exile: 
$[\mathrm{T}]$ here is perhaps a nagging suspicion among our elders that we may have found another country. A country to live in and die for... that offers sustenance but demands commitment and sacrifice. A focus for youthful passions luring us away from more mundane and safer concerns of commerce and clan. A country that again dangles the promise of martyrdom which only ends in betrayal - all, that is, that an exile must at least partially abandon home. 'Never again' he tells himself and admonishes his children - 'this is not our war, or yours, we fought ours many seasons ago so you may live in peace.' At some point the migrant knows he must choose to live fully as a person without a country if only to survive the vicissitudes of uprootedness. He bends with the wind and profits on cynicism. He says 'no' to everything that forced him to leave home and family - war and patriotism. He dreams that his children will be citizens of the world. It is a pipe dream of course, for one cannot love humanity without sympathizing with a neighbor brutalized by systemic oppression; because nationalism is only the concrete expression of our humanity in a particular historical context. This he knows. He knows this dream of unbelonging is the last thing he must surrender with grace to time. (Ong 7-8; emphasis added)

The passage shows the vicissitude of being separated from one's homeland. His return to his motherland as an act of home hunting is not without complications. The idea of home, in this sense, is blurred. Home, traditionally, is exclusive to a particular locale. However, in this case, home is treated not just as a physical or social manifestation but also as an ironic conceptual signification in relation to unbelonging, of having the idea of belonging despite traversing different physical locales. Therefore, his diasporic consciousness "generally reflects a degree of unease with cultural identities in [his] current place of residence" (Cohen 71). Aside from the concept of home, the passage raises issues concerning nationalism. Given the circumstance of the Victorianas, Jeffrey Tantivo illumines that the concept of nation does not exclusively stem from ethnic commonalities. The prospect of noncitizenship being changed or challenged remains an option but not by obliging the state to take them into the fold. On the contrary, freedom from citizenship by becoming citizens of the world enables a paradoxical revolution in the diasporic landscape: of embracing exile and unbelonging. Critic Shirley Lua concurs:

The image of "bending in the wind" suggests resiliency and resignation. He goes where the wind moves. Thus, he is able to look forward to the dream, that one day he or his offspring will become "citizens of the world," rejecting the notion of "belonging" to just one place, one home, one country. This is, as Edward Said has argued, a "place for all the rendezvous of victory" for "[m]arginality and homelessness are not ... to be gloried in; they are to be brought to an end." (139)

However, Lua's point can be further extended. Jeffrey's identity politics also signifies the unmaking of national boundaries and the unbounding of bordered 
perspectives on identity and belonging. Looking at this imagery through the lenses of the diaspora, locations and places become ethereal encounters. One's "home country and the country of residence [become] 'ghostly' locations and the result can only be double depoliticization" (Radhakrishnan 123). Diasporic individuals, therefore, transcend boundaries in order to grapple with the consequences of dislocation, displacement, and even movement. In associating one's self to multiple trajectories of homes, double depoliticization occurs through unbelonging and consequently becoming citizens of the world.

Jeffrey desires knowledge about his origin. Alfonso Ong, one of the pioneers in immigrating to the Victorianas feels that piecing together the fragmented past is essential because Jeffrey feels disconnected from his roots due to his exile. Jeffrey supposes that his intuitive attachment for his personal history paves the way for the fusion of his severed past, perplexing present, and uncertain future. However, this hunger for knowledge of his roots and intimacy with the past and home country submerges Jeffrey to an unthinkable abyss of deceit and fraud. It is said that "the feeling of [being] deracinated in the diaspora can be painful, but the politics of origin cannot be the remedy" (Radhakrishnan 128). True enough, the revelations about his familial affairs and roots do not satiate his desire in knowing what he has been and what he is to be. On the contrary, it impels him to suppress the existence of his past because it entails opening the wounds that are seemingly closed. Alfonso Ong, as part of the older generation of Chinese immigrants in the Victorianas, appears to have a key toward unlocking the severed link between the past and present generation. Arjun Appadurai drives a point on why the past of diasporic beings are supposedly suppressed. He argues:

The past is now not a land to return to in a simple politics of memory. It has become a synchronic warehouse of cultural scenarios, a kind of temporal central casting, to which recourse can be had as appropriate, depending on the movie to be made, the scene to be enacted, the hostages to be rescued. (29)

Hence, working for Alfonso Ong, Jeffrey emotionally tells Mailin Berwani that "[Alfonso Ong] is my father, my blood" (Ong 395). As a rejoinder, Mailin says, “There's no such thing as blood, Jeffrey. He's not your father, you are nothing to him but a pair of kidneys. You won't inherit anything from him but his crimes" (395). Consequently, Jeffrey takes part in the attempt to eliminate those who betrayed him and his unwanted past. By attempting to destroy his opponents, he perceives that the unwanted past is kept suppressed thereby averting further anguish as a result of unwelcomed discoveries.

While Jeffrey is drowning in the river after the foiled bombing of the wake, several epiphanies have emerged. These epiphanies articulate the suppressed 
memories and truths about Jeffrey Tantivo's being. These recollections of images feature elements of his diasporic identity, withheld by his opponents and even his biological father:

As we neared the light a figure met us. It was Carlos Tantivo. "Father," I said, he embraced me and then images from my past swirled around me. I was a child once more with my parents and Jasmine. Then I was a young man playing basketball for the University of San Ignacio, slam-dunking for the first time. Next, I was in the Kublai Khan with my friend guzzling beer, making love to Hortensia. Then I was roaming the streets of Manila alone and lost. I was now flying home to the Victorianas, joining Ignacio, Kate, Jennifer; firing the shot that killed a man, removing the bomb that would have killed many more. I relieved my life in an instant; all the loves and hatred, the times of anger and of remorse, all the choices made and chances lost. I felt a deep, profound sadness that slowly turned into an acceptance of the inevitability of certain things. Then there was peace and joyfulness, though tinges with anxiety and restlessness. (Ong 413-414)

In this momentous and succinct reminiscence of cherished memories, Jeffrey Tantivo is unburdened with searching for his lost past. The acceptance of the inevitability of certain things proves to be a turning point away from his fixation in putting the Victorianas and his past into order. He left the island, again, bound for the Philippines for his second exile, by choice. However, in this exile, he feels more anchored and self-assured in the midst of ambiguity. He proudly proclaims, "I speak for all of my people who drift in a sea of uncertainty. I live for all who keep vigil in the night of the world awaiting a certain daybreak" (Ong 425). He is now, more than ever, confident in his return to exile than his earlier return from exile.

\section{TERRITORIALIZATION AND DETERRITORIALIZATION: EXPLORING THE SPACES OF DISPLACEMENT}

In relation to the search for root of diasporic beings, space is also another important aspect in the diaspora and such can be subjected into two processes: the territorialization of location and the deterritorialization of people as exemplified in the narrative. Alfonso Ong, Alfredo Sy, and Carlos Tantivo have travelled to the Victorianas due to some unfavorable events in Indonesia. It is important to know the event that compelled them to journey towards the Victorianas. Similar to the Philippines, at one point in the history of Indonesia, the Chinese were entirely loathed. In the case of the Philippines, according to Escoto, the Chinese were subjected to special taxation, restrictive legislation, extortion, physical abuse, and damage to property because of their strong economic visibility (53). Hence, they were expelled from the islands of the Philippines. In similar vein, the Chinese in 
Indonesia were subjugated to the same treatment but worse. Mass killing of the Chinese transpired in Indonesia and this event was called the Batavia massacre of 1740. In the narrative, Alfonso Ong narrates his and his sworn brothers' tribulation in Indonesia to Jeffrey Tantivo:

\footnotetext{
"Young people these days are always demanding time from old people. Time is the last thing we have enough of," Alfonso went on. "I was on the same boat with him, the last one out of Indonesia before the killings. We were smuggled out at night aboard the fishing vessel. Paid a fortune for it. These Javanese sailors fed us nothing but spoiled sardines for three days and night. Kept asking us about the mountains of gold we'd stashed away. We were never sure when they'd throw us into the sea as fish bait. (Ong, Embarrassment of Riches 113)
}

Focusing on massacre as a form of controlling the Chinese population in the Philippines, such also occurred in a large scale in 1639. Tong posits that during the said year, almost the whole Chinese population of Luzon perished (202). This event transpired because of a revolt of the Chinese in the area that lasted for four months.

In the narrative, Alfonso Ong is possibly alluding to the Batavia massacre in Indonesia. The Chinese are displaced beings from their place of origin, which entails deterritorialization of the diasporic Chinese not having a land to call their own. The result of displacement can be likened to being discarded-politically and socially. Despite being away from home, the immigrant Chinese did not weaken their bonds as it is kept alive by kinship and dialect ties (Chin-Hwang 289). A country or locale, as a point of reference or home, becomes an illusion that diasporic individuals invoke through nostalgia - of being physically deterritorialized from their land of origin and at the same time territorializing their previous locale through memory. "It is in this fertile ground of [territorialization and] deterritorialization, in which money, commodities, and persons are involved ceaselessly chasing each other around the world" (Appadurai 37). Their journey towards the Victorianas provides them a space for territorialization, of commencing a new beginning and planting their roots in a new land.

Alfredo Sy, the contemporary of Alfonso Ong and Carlos Tantivo, has been able to establish his domain in the Victorianas through the A. Sy Enterprises and Megalomalla. Unfortunately, Alfredo dies due to brain cancer before the mall is inaugurated. Nevertheless, Megalomalla, as the bulwark of the Sys, is highly striking in terms of magnificence. Lua critically examined Megalomalla as a significant feature of the narrative and states:

Megalomalla is Parian in its extreme, ultra-postmodern, and super high-tech state. It is the pinnacle of excessiveness, opulence, and grandeur - truly an embarrassment of 
riches. A most fitting emblem of its extremeness is the high-tech crematorium-cumcrypt. The novel describes the glass and brass crypt, "where the ashes of the corpses roasted in the adjoining crematorium were deposited in brass-paneled glass containers flanked by small video machines which visitors can operate to watch specially produced videodisc biographies of their dear departed." (135)

This display of grandiosity possibly asserts the notion that the Chinese who landed in Southeast Asia are highly adept in the craft of economic mobility. They are refugees from another nation who have started with nothing but ended with almost everything in a different land. In this case, the Victorianas is territorialized by the Sys through the formation of the 150-hectare Megalomalla.

In conjunction with Alfredo Sy's creation of an empire in the island, Jennifer Suarez Sy also adheres to such by obtaining the presidency of the Victorianas. By being the CEO of A. Sy Enterprises and at the same time the president of the country, she "turned the presidency into another franchise of A. Sy Inc." (Ong 288). As she obtained multiple dimensions of territories, politically and economically, her leadership is short-lived. Owning the conglomerate and presiding over the highest position of the land entail encompassing resistance by those who have been deterritorialized-the Chinese men who subscribe to patriarchal orthodoxies.

She has taken more than what she can possibly consume in terms of influence and power. By extending her territory politically, the demise of her regime is inevitable. Generally, it is not the territory of the Chinese woman to take part in the political affairs of the land as have been depicted in the narrative. As Alfonso Ong quips, they "will never allow her to rule" because "she is a Chinese, [and] she is a woman" (Ong 169). True to his word, Jennifer Sy has "nothing to gain but everything to lose" in satisfying her desire for creating territories (169). Women in Chinese diasporic societies tend to encounter challenges in terms of asserting power and destabilizing patriarchy. However, it should be noted that Jennifer Sy's position of power in the narrative is hybridized. The Victorianas afforded her the position to assert her identity as a woman in power, but those who seek to impose old patriarchal structures and traditions altered her practice of power.

Jennifer Sy, as a Chinese Victoriano woman, is prevented in maintaining her stature as possibly the most powerful woman in the Victorianas despite the fact that she has won the elections legitimately. On the other hand, Jeffrey Tantivo, as a Chinese Victoriano man, has been appointed as the replacement of Jenny. Additionally, the appointment can even be considered illegal because it is a result of a coup d'état. Traditionally, in Chinese culture, the place of women "was in the home, and their contribution to the world was in their reproductive capacity" (Pan 191). Although Jennifer Suarez Sy, as a Chinese Victoriano woman, exists in a 
different world-in a diasporic world where convention may conceivably be more liberal-patriarchal forces still subsist. Lynn Pan provides a comparison on how women are treated in diasporic societies. She argues that womanhood in Chinese societies outside China are less stringent since an immigrant Chinese woman can stand outside the prescribed feminine convention as compared to the one in the home country (191).

Pan's argument possibly counters Alfonso Ong's biased opinion that Jennifer Suarez Sy will not succeed as president. Jenny is able to partly supersede patriarchy by ascending to the presidency. Alfonso Ong himself, on the other hand, is the patriarchal force that has destabilized Jennifer Sy's legitimacy in ruling over the land. Tracing Alfonso's origin, he is born in a traditional Chinese society and therefore seeks to perpetuate the same conduct in the Victorianas.

Another display of territorialization is through Alfonso Ong's acquisition of the Burias and the aboriginals that live in the island. Alfonso Ong is hailed as "Apo Dilaw" by the aboriginals. The term when translated to English roughly equates to the Yellow God, and is reminiscent of the Yellow Emperor of China, Huangdi. They call him the Yellow God because the people in the island have no equivalent term for emperor. Notably, this may possibly be considered as hybridizing history through the juxtaposition of the Apo Dilaw of the novel and the Yellow Emperor of history. It is said that Huangdi was the first emperor of China to unify the warring states. In the narrative, Alfonso Ong has a similar goal but it is not of unification but territorialization - the construction of Burias as the final frontier that is independent from the Victorianas. Furthermore, the soothsayer in Amoy has predicted that he is "destined to be king" (Ong, Embarrassment of Riches 171). Ong describes his territorialization process:

When we came to the Victorianas, your father and I, we didn't know what to expect. We accepted what we found and built on it. The Victorianas is a dish concocted by many cooks with recipes that don't always mesh. Now, I fear the time your father had long anticipated is near. I'm trying to keep things from blowing apart, but I think it's beyond me or anyone else now. Every time I visit the island I sense discord, destruction. Here is our chance to rebuild. (173)

Through the guise of rebuilding an island, Alfonso demarcates his territory as different from the main island. However, it is revealed that his island is not being built in the spirit of goodwill. The city-in-the-making by Ong is fabricated as a big drug laboratory producing methamphetamine hydrochloride, colloquially called in the Philippines as shabu. 
Looking at the role of the Chinese in the Victorianas, they are individuals who have been dislocated through the process of migration, immigration, and exile. It can be presumed that Alfonso Ong, Alfredo Sy, and Carlos Tantivo originated from China. Then, they travelled to Indonesia and ultimately landed on the shores of the Victorianas. Through these several dislocations, the cycle of territorialization and deterritorialization arise. Situating this argument to the historical contingencies of the diasporic Chinese, they sought to territorialize spaces to create locales dedicated to their cultural and economic practices. For the Chinese in the Philippines, territorialization is best exemplified by the Parian during the Spanish colonial era and consequently Chinatown. This example signifies that diasporic beings are "scattered and regrouped into new points of becoming" in spaces both familiar and unfamiliar (Braziel and Mannur 3).

It is not seen in the narrative that they desire to go back to Indonesia, China, or any other place of origin. This point substantiates that home does not necessarily mean one's place of origin. It is up to the diasporic being whether to accept the host land as home or to further drift away in nostalgia, seeking the remnants of the land they once knew. The space of dislocation collapses geographical and geopolitical boundaries and blurs the lines among the different ideations of the sojourners and their succeeding generations. To conquer new lands or ideas are intrinsic for those who have been displaced and deterritorialized giving birth to dominant and minority positions. Lastly, by establishing new territories, new diasporic panoramas are created. In concurrence with this claim, Bromley argues that "each deterritorialization (of people itself; of form or genre) constitutes and extends the territory itself; it is a way to keep on opening up meanings" (100).

\section{DIFFERENCE AND DIFFÉRANCE: DISTORTING AND DISRUPTING IDENTITIES IN THE NARRATIVE}

Putting into perspective how identities are fashioned and crafted in representation, Stuart Hall and Jacques Derrida posit that the concept of identity is engaged through a cycle of continuous change. Change for diasporic beings may be influenced by the concept of home hunting and the search for cultural roots. Identities in the narrative are suspended from adhering to the traditional notion that it is a pure and unchanging essence. However, since the novel is an artistic production in language, the concept of identity is distorted, hence, fulfilling the hybridization of Chinese culture and representation. Stuart Hall, borrowing the concept of Jacques Derrida's deconstruction, opines that "meaning continues to unfold, so to speak, beyond the arbitrary closure that makes it, at any moment, possible. It is either always over- or underdetermined, either an excess or a 
supplement. There is always something 'left over"' (240). Through this concept, it can be deduced that the identities of the characters in the narrative are molded into different significations that veer away from one true meaning or extraction. Identity, then, is contingent but with arbitrary stops that enable depiction of it in a particular context.

Jennifer Suarez Sy is a depiction of identity construction that is in progress, through hybridity and multiplicity. Lua describes her characterization:

And Jennifer Suarez Sy, of Chinese descent, the heiress to the multimillion conglomerate A. Sy Enterprises, would become the short-lived President of the tenth republic of the Victorianas. She is also a die-hard Trekkie, who establish a Liberation ranch run like a religious convent. In her school are educated on Star-Trek data and all mathematical scientific paraphernalia necessary to mold (or brainwash) them into blue-blooded Trekkies. Her philosophy is a muddle-concoction of New Ageism, free enterprise, and neosocialism, the tenets contained in the blue book (shades of Maoism) entitled Blue Revolution: The Final Frontier. (134)

This passage shows that Jennifer Sy may possibly be an inversion of the Marxist struggle, a deconstruction of the Maoist ideals which includes hybridization of neosocialism and New Ageism. This vision is reinforced through the painting described in the narrative "of a Chinese-looking woman garbed as a Maoist Red Guard, stepping on the head of a pied-colored dragon and waving a blue book" (Ong 29). The Maoist Red Guard, evocative of the political revolution in China, is destabilized by the inclusion of the blue book instead of the traditional red book associated with communism in China.

In relation to identity, the blue book is a sign that initiates an inquiry as to what the Chinese identification ought to be. Through this inverted depiction, Chinese identity through Jennifer Sy is destabilized, opening points of divergence in undertaking subject positions. Notions systematically associated with the diasporic Chinese are differed in the narrative which allows resistance. The blue revolution that is espoused by Jennifer Sy is the deculturation of the historical red revolution and it is an articulation of an oppositional identity. As a form of establishing new identifications, the diasporic Chinese take on subject positions that may be considered alternative to common conception of what the Chinese are and ought to be.

In a similar vein, Aldoux Chang is depicted in the novel as an eccentric fortuneteller who believes in New Ageism. Bizarrely, he mixes oriental mysticism, digitized astrology, and even pseudo-scientific jargon to profess his exemplary skill in manipulating and managing spirituality. Also known as the reincarnation 
of Ibarra Wang, Aldoux Chang is the spiritual councilor of Jennifer Sy and he is described as a fortyish broad-shouldered Chinese mestizo with clear skin as a courtesan.

Luna Cleto Sicat opines that Aldoux Chang is an enigmatic "hoax artist" who is a master of deceit, a Chinese Machiavelli (122). Building on the argument of Sicat, Aldoux Chang's eccentricity is simply a guise in ensuring survival in the dystopic Victorianas. In actuality, Aldoux Chang does not side with anyone except himself to advance his interests. He pretends to be an adviser to Jennifer Sy but at the same time vehemently maintains his companionship with Lao Ong. Aldoux, therefore, is in the best position as he has played the game of politics so well-like the revered political and wartime strategist Niccolò di Bernardo dei Machiavelli.

Characterized as such, Aldoux Chang is also a portrayal of hybridization with the combination of eastern-leaning ideas and western-influenced practices such as oriental mysticism, computerized astrology, and pseudo-scientific jargon. However, the mixture is not well taken as it leans towards becoming a caricature, his ritual being described as a combination of a Taoist exorcism and a heavy metal rock number. The deconstruction takes place in the collision of images and practices that are not enmeshed properly which makes Aldoux Chang an adviser with a distorted outlook and representation, or simply a hoax. This perverted portrayal of the character foregrounds the sense of creolization pertaining to identities - of creating new variations of subject positions, clearly a deviation from essentialism and a continuation of the process of differing.

In another case, Jeffrey Tantivo's baptismal in the mountain shows how religious identification is highly fluid and unstable as well. Jasmine Tantivo, bringing him to the mountains necessitate the acceptance of the customs of the millenarian group. Interestingly, the practices of the group are quite unconventional. The group is led by priestesses who conduct rituals such as spiritual cleansing and baptismalmixing Catholic and indigenous beliefs:

The Mass was conducted in Latin and the priestess, decked in bluish robe and what looked like a cardinal's miter, had her back to the congregation. Here was a cryptic version of a pre-Vatican-reform Catholic Mass. The chapel wall behind the altar was painted over with millenarian iconography: a triangle containing a huge eye, symbolizing God the Father; a native woman in a flowing white robe, God the Mother; Jesus Christ; Carlos Remedios; a white dove, representing the Holy Spirit; and a golden lizard that signified Kapangyarihan. Baroque music emanated from a bamboo organ. It was an eclectic blend of nativist and Christian beliefs, of divinity and earthly heroism, of myth and history. [...] It conjured the primal knowledge of the race; ancient yet ever present. And in some indefinable manner, prefigured the future. (Ong 148) 
The elements present in the ritual are constructed as a signifying unity although differing in origins, mending the fissures of indigenous beliefs and the Catholic religion. It is both mythical and historical perhaps due to the inclusion of Carlos Remedios, the Victorianas' national hero, as a spiritual signifier. Through this point, it is a production of a new order that does not reproduce the social structure of the old system considering that women are at the forefront of the religious exercise and the inclusion of God as a woman. The millenarian congregation and religious practice is a noteworthy deviation from Catholicism, a deconstruction of the conventional gendered patriarchal structure of religion. In general, Jeffrey Tantivo, with the Chinese name Kok Yung, is also named Maylaan by the millenarians:

"Will our brother, Maylaan, please approach the altar," the priestess called out to our gathering. [...] "Do you renounce Dayuhan and the darkness of his ways?" the priestess continued. "Do you accept Jesus Christ, the universal savior, Carlos Remedios, the savior of our race, spiritual offering of Kapangyarihan?” (Ong 148-149)

These actions further demonstrate the subject positions that he assumes, from changing his name to even accepting the religious imposition of the millenarians. Identity in this sense is a heterogeneous endeavor because of the "existence of differences and differential relationships" among the characters and other elements in the narrative (Lowe 138). Jennifer Sy and her blue revolution, Aldoux Chang and his hybridized oriental-western fortune cookie spirituality, and Jeffrey "Maylaan/Kok Yun" Tantivo and the millenarians are illustrations of deconstruction of identifications that lead to the undertaking of subject positions. The conceptual signification of being Chinese and its supposed purity is disrupted and the hybridization of Chinese elements is made possible. Likewise, Hall opines that "identity [is] unstable, metamorphic, and even contradictory-an identity by multiple points of similarities and differences" (233).

\section{AN EMBARRASSMENT OF RICHES: A COUNTERFACTUAL SPECULATION OF PHILIPPINE HISTORICAL EVENTS}

Appropriately categorized under the genre of speculative fiction, a sub-genre of science fiction, the narrative creates an alternate world where the existence of a new faux nation is made possible. Furthermore, the narrative also features aspects of other genres such as satire, domestic melodrama, crime novel, and political novel (Hau, The Chinese Question 267). Hellekson, on the concept of alternate history, states that: 
The alternate history asks questions about time, linearity, and the implicit link between past and present. It considers the individual's role in making history, and it foregrounds the constructedness and narrativity of history. Typically, the nexus point refers to "our" world, but in some instances authors instead create an entirely different world or push the action so far into the past or future that tracing the effect of the changed nexus point becomes difficult or impossible. (453)

Though non-existent in reality and leaning towards speculation, the Victorianas is similarly patterned to the historical underpinnings of the Philippine nation in terms of language, culture, and even political scene to establish a nexus point. The generic form of the novel actualizes "alternate states of existence to those experienced in [the] real world" (Hills 433). Focusing on the island-nation perpetuated in the narrative, it is "ironically a mishmash, quintessentially, and absurdly postmodern - discontinuous conjunction" (Lua 134). Her paradoxical description of the dystopic Victorianas as a discontinuous conjunction is precisely suitable in revealing the techniques used to propel a compelling speculation in the binding of history and fiction.

The simultaneity of different languages in the island-nation reflects the cultural and linguistic diversity of the narrative, similar to the case of the Philippines. Sicat argues that the co-existence of languages in one cultural system, or heteroglossia, gives birth to the nation. She further states the languages present in this faux nation shed light on each other because the phenomenon allows the possibility of comparison and translation. The language becomes national due the possibility of comparison. The Victorianas is home to many languages that are derived from colonial contact or native construction. Sadagat, the pre-conquest language, "belongs to the Malayo-Polynesia family and bears much similarity to Bahasa and to the Tagalog languages of many Filipinos" (Ong, Embarrassment of Riches 13). The ultimate binding agent of the different languages present in the nation is Victoriano, a mixture of "Spanish, Portuguese, English, and Chinese" (13). Victoriano, as a language, is made an effective speculative cultural element by its juxtaposition with historical events such as the colonial encounters with the Spanish and Americans as well as early commerce and trade with the Chinese.

The specter of the Philippines abounds in the narrative; it is an auxiliary reference to build up the authenticity of the Victorianas. Though "a mere dot in an imaginary world map, Victorianas possesses features of an island that repeats itself, as any one of the 7,107 islands of the Philippine archipelago that would repeat itself in the vastness of the Pacific" (Lua 133). Other subjects that the narrative illustrates are of indolence and historical revolt, again evoking the Philippine presence: 
The Spanish governor-general in Manila - who had nominal jurisdiction over the Victorianas - often saw the island as little more than a place of exile for rabble-rousing Filipinos or an occasional source of slave labor and conscripts. Victoriano laborers, however, often proved even more indolent than Filipinos when working for slave wages, and twice when Victoriano men were conscripted to put down revolts in the Philippines, more than half the army deserted so that both practices were eventually abandoned.

(Ong 15)

The history of the Victorianas is being constructed on top of Philippine history, a factual entity, further removing the demarcation between history and fiction. Through this generic appropriation of the author, "the reader becomes the historian, piecing together historical traces, with the payoff being the recognition of specific points of divergence" (Hellekson 454). Hence, the literature/history binary is invoked on the part of the reader, realizing the extent of factuality and degree of fictionality. Sicat, on the novel's form, concurs that the narrative raises the question of historicity and the readers given the duty to patch the fragments of truth and pieces of history to test its logic.

This incessant orientation toward the Philippines is a narrative experiment that tests the limits of this specific fictional history. On the other hand, the simultaneous formation of imagined communities enables an outward identification of the ills of the Philippines through its spectral presence in the Victorianas. This depiction leads to another point in the generic description of An Embarrassment of Riches, specifically in the narrative's emphasis on the social ills and moral decomposition of the nation-the formation of dystopia. The narrative "focuses on the terrors than the hopes of history ... not to undermine Utopia but rather to make room for its reconsideration and refunctioning in even the worst of times" (Murphy 474).

The Victorianas is a nation plagued by political turmoil and uncertainties as depicted by cyclical civilian and military power struggle, bloody and unsuccessful elections, and incessant anarchy. The mechanism of disorder reverberates throughout the progression of the narrative. Azurin's dictatorship has reduced freedom in the land while he enjoys the company of a lot of women. His death is even puzzling as he has been found dead inside the presidential bathtub holding his penis. The conduct of elections in the Victorianas is neither orderly nor peaceful. An attempted assassination has occurred specifically targeting Jennifer Suarez Sy but is successfully foiled. Jennifer Sy, who won the election, is later discovered to be hooked on marijuana that Aldoux Chang supplied.

Jennifer Sy's government is crippled by a coup d'état instigated by his halfbrother. Megalomalla, initially a high-tech mall exuberating opulence, became a squatter's colony at the end of the narrative. Mike Verano, a spiritual leader, is a 
heartless villain displaying unmerciful acts against those who are non-believers. Alfonso Ong lengthens his life by taking the body parts of the aboriginals and keeping his island afloat economically through the production of drugs specifically methamphetamine hydrochloride. Also, Sicat points out that war is considered an insignificant event for Victorianos and the media in the nation is without ethics or objectivity (116). Condensing all of these occurrences in one narrative produces a glaring dystopia. In general, the Victorianas exudes "disruptions, dissonance, torrents, tremors, violence, and vitality" (Lua 133).

An Embarrassment of Riches is a speculative narrative that is inspired by the novels of Rizal, Noli me Tangere and El Filibusterismo. Looking at the plot of the latter, it is evocative of Simoun formerly Crisostomo Ibarra who returns to the Philippines after being in exile abroad. His return to the Philippine is not of optimism but of revenge against those who did him wrong. It is best to recall significant events in Noli and Fili to see the frame of similarity between Rizal's novels and Charlson Ong's novel. It is the goal of Crisostomo Ibarra to build a Spanish language school in the Philippines in order to establish literacy among his people. He firmly believes that such will help them surpass their state of hardship and poverty.

However, this goal is negatively received by those who are in the position, specifically the Spanish Friars. Crisostomo also realizes that the remains of his father have been desecrated. He searches for the remains of his father and recognizes that it has been moved to a Chinese cemetery. The corpse of his father has ended up floating in a river. In addition, due to his reformist tendencies, he is blamed for a revolt that transpired and is consequently arrested and imprisoned. Maria Clara thinks Ibarra has been killed during the arrest and therefore admits herself to the nunnery. On the other hand, Crisostomo thinks that Maria Clara has betrayed him. Consequently, Crisostomo goes into exile and later returns as Simoun. Simoun on the latter chapter of Fili, conceptualizes an attack on the wedding of Juanito and Paulita Gomez. Specifically, Simoun wants to use an ornate kerosene lamp as an explosive to kill everyone in the vicinity. The plan, however, is foiled.

Considering An Embarrassment of Riches, Jeffrey Tantivo takes the form of Crisostomo Ibarra and Simoun. Similar to the former, he is entirely enthusiastic in reforming the Victorianas as a nation by being part of Jennifer Sy's campaign. With Jeffrey's return to the Victorianas, he discovers that his father's remains were violated. Furthermore, as his journey began to turn sour and bitter each passing day-realizing the rottenness of Victoriano politics-he became a violent revolutionary. Analogous to the ornate kerosene lamp of Simoun, Jeffrey Tantivo and his cohorts have a similar item but in the form of his father's urn. During the 
cleansing ritual of his father's remains, the urn is supposed to explode. However, identical to Rizal's novel; the deed is thwarted and the damage is minimal.

The parallelism of Rizal's novels and An Embarrassment of Riches calls attention to the difference of treating a similar subject-of reforming a nation for the better. If Rizal's novels are situated in 19th century Philippines through the lens of realism, Charlson Ong's novel speculates on a new nation built on Philippine history but positioned in an indeterminate temporal state. Hence, Luna Cleto Sicat's claim that An Embarrassment of Riches is a metafictional narrative is true since the novel is possibly a mimetic transformation of Rizal's novels into the speculative mode (119). Clearly, Rizal's novel is a social commentary of the ills of the Spanish treatment of the Filipinos during the 19th century. Possibly, Charlson Ong has the same goal in mind in the creation of the novel. Building on Sicat's claim that the novel is an analysis of the ills of the Filipino nation, it is can be considered that the novel is criticizing and even parodying the country during Cory Aquino's regime. It can be recalled that during Cory's term, several coup d'état, NPA insurgencies, numerous power outages, and similar unfortunate events transpired.

Charlson Ong's technique in the development of the Victorianas is successful through the sewing of fiction and history and the Philippines and an alternate reality. By means of creating and hybridizing the aforementioned narrative elements, it gives rise to "certain aesthetic and cognitive effect which is not merely estrangement - our 'own' world or time being seen anew - but more precisely an ontological disruption and decentering" the reader's sensibilities (Hills 435). As compared to post-modern text, the ontological shock of a speculative narrative such as this is more reader-friendly (Hills 435). The novel "invents an islandscape - a community with multifold attitudes, personalities, movements, currents, ruptures and rhythms - as a way of reconstructing complex minority history" (Lua 140). As for the generic form, it extrapolates the Philippines' past to create an alternate version of history which is the Victoriano present. Despite the narrative being counterfactual, it encourages the reader to see history through narrativity and not of factuality. Hills argues:

Despite this spin on SF counterfactuality, such alternate story stories work in similar ways to other possible worlds, in that they compel us to see familiar events (this time, narrative rather than historical) in a radically new light. Aesthetically and cognitively, such fictions again provide the thoughtful thrill of "ontological shock." (440)

In this sense, the truth-value of history is challenged by the creation of an alternate reality. Hau illumines that "the richly imagined details of history, people, and everyday life in Las Victorianas incite comparisons with the Philippines" (The Chinese Question 273). Charlson Ong puts forward a structured imagination of a 
nation and diaspora through the specter of Philippine historical and even literary contingencies. Consequently, it allows for further introspection as regards the position of the Chinese in the Philippines. The narrative framed as a speculative alternate history of the Philippines allows for a compelling critique of the curious relationship of the Chinese diaspora, Philippine nation, and Southeast Asia.

\section{CHARLSON ONG AND THE REIMAGINATION OF THE CHINESE DIASPORA}

It can be said that the Chinese diaspora is one of the longest and most persistent diasporas (Hu-Dehart 432). An Embarrassment of Riches provides an encompassing reimagination of the Chinese diaspora situated in the Southeast Asian region. Through the creative speculation of Charlson Ong vis-à-vis the Chinese diaspora, hybridity has been molded as a form of newness of conceptualizing identities; definitely "the adaption of means of diverse provenience to new ends" (Kapchan and Strong 241). Following Stuart Hall's notion that identity is not an essence but a position, diasporic Chinese identities in the narrative are differed and disrupted strategically to point out that concept of identity is not static. The characters in the narrative have been shaped into different significations beyond a single inert meaning. Identity is contingent but with arbitrary stops that enable depiction of it in a particular context. Furthermore, identity is destabilized and therefore exposes places from which to speak or points of divergence in undertaking subject positions.

The novel is the embodiment of cultural amalgamation owing to the complex diasporic experiences. The narrative entails traumas and ruptures that celebrate their resiliency despite displacement. Usually marked as minority culture in the Philippines, the diasporic Chinese are given a place of articulation and a position of enunciation through these fictions that offer spaces of dissension against essentialized perspectives of conceptualizing identities. Therefore, the identities

of the Chinese affected by the diaspora are heterogeneous since differences and differential relationships exist and the supposed purity of Chinese identities is disrupted. 


\section{Notes}

1. Hybridity, in the context of the diasporic Chinese, refers to the state of being inbetween cultural identification-a sense of double-consciousness.

2. The concept of a hybrid heritage as contextualized in the narrative is a position of straddling dual cultural orientations. 


\section{Works Cited}

Appadurai, Arjun. "Disjuncture and Difference in the Global Cultural Economy." Theorizing Diaspora, edited by Jana Evans Braziel and Anita Mannur, Blackwell, 2003, pp. 25-48.

Braziel, Jana Evans and Anita Mannur. "Nation, Migration, Globalization: Points of Contention in Diaspora Studies." Theorizing Diaspora, edited by Jana Evans Braziel and Anita Mannur, Blackwell, 2003, pp. 1-22.

Bromley, Roger. Narratives for a New Belonging: Diasporic Cultural Fiction. Edinburgh UP, 2000.

Cohen, Robin. "Social Identities and Creolization." Diasporas: Concepts, Intersections, and Identities, edited by, Kim Knott and Sean McLoughlin, Zedd Books, 2010, pp. 69-73.

Ching-Hwang, Yen. Chinese in Southeast Asia and Beyond: Socioeconomic and Political Dimensions. WSPC, 2008, ProQuest elibrary, Accessed 22 Nov. 2016.

De Chavez, Jeremy. “The Traditional and the Modern in Jessica Hagedorn's Dogeaters." The Explicator, vol. 48 no. 2, 2017, pp. 84-88.

Escoto, Salvador P. "A Supplement to the Chinese Expulsion from the Philippines, 17641779." Philippine Studies, vol. 48, no. 2, 2000, pp. 209-234.

Gilroy, Paul. Against Race: Imagining Political Culture beyond the Color Line. Belknap Press of Harvard UP, 2011.

Hall, Stuart. "Cultural Identity and Diaspora." Theorizing Diaspora, edited by Jana Evans Braziel and Anita Mannur, Blackwell, 2003, pp. 233-246.

Hau, Caroline S. The Chinese Question: Ethnicity, Nation, and Region in and Beyond the Philippines. Ateneo de Manila UP, 2014.

--. Necessary Fictions: Philippine Literature and the Nation, 1946-1980. Ateneo de Manila UP, 2000.

Hellekson, Karen. "Alternate History." The Routledge Companion to Science Fiction, edited by, Mark Bould, et al., Routledge, 2009, pp. 453-457.

Hills, Matt. "Time, Possible Worlds, and Counterfactuals." The Routledge Companion to Science Fiction, edited by Mark Bould, et al., Routledge, 2009, pp. 443-441.

Hu-Dehart, Evelyn. "Afterword: Brief Meditation on Diaspora Studies." Modern Drama, vol. 48, no. 2, 2005, pp. 428-439, EBSCO, Accessed 19 July 2013.

Huggan, Graham. "Post-coloniality." Diasporas: Concepts, Intersections, Identities, edited by Kim Knott and Sean McLoughlin, Zedd Books, 2010, pp. 55-58.

Kabir, Ananya Jaharana. “Diasporas, Literature, and Literary Studies." Diasporas: Concepts, Intersections, Identities, edited by Kim Knott and Sean McLoughlin, Zedd Books, 2010, pp. 145-150.

Kapchan, Deborah A. and Pauline Turner Strong. "Theorizing the Hybrid." The Journal of American Folklore, vol. 112, no. 445, 1999, pp. 239-253, JSTOR, Accessed 19 Dec. 2013.

Lowe, Lisa. "Heterogeneity, Hybridity, Multiplicity: Marking Asian-American Difference." Theorizing Diaspora, edited by Jana Evans Braziel and Anita Mannur, Blackwell, 2003, pp. 132-155. 
Lua, Shirley. "The Repeating Parian: Tropic Positions of Chinese-Philippine Fiction in English." Writing Asia: The Literatures in Englishes, edited by Edwin Thumboo and Rex Ian Sayson, Ethos Books, 2007, pp. 129-145.

Murphy, Graham. "Dystopia." The Routledge Companion to Science Fiction, edited by Mark Bould, et al., Routledge, 2009, pp. 473-477.

Ong, Charlson. An Embarrassment of Riches. Philippine Centennial Commission, 2000.

-.. "China is in the Heart." Philippine Free Press, 10 Oct. 1992, pp. 44-45.

Pan, Lynn. Sons of the Yellow Emperor: A History of the Chinese Diaspora. Little Brown, 1990.

Radhakrishnan, R. "Ethnicity in the Age of Diaspora." Theorizing Diaspora, edited by Jana Evans Braziel and Anita Mannur, Blackwell, 2003, pp. 119-131.

Tong, Chee Kiong. Hybridization and Chineseness in the Philippines. Springer, 2011. 